\title{
Treatment of the facial basal cell carcinoma with the use of photodynamic therapy: A case report
}

\section{Leczenie ogniska raka podstawnokomórkowego skóry twarzy z użyciem terapii fotodynamicznej - opis przypadku}

\author{
Mateusz Trafalski ${ }^{1, B, D}$, Klaudia Kazubowska $^{2, C, D}$, Kamil Jurczyszyn ${ }^{1, A, F}$ \\ 1 Department of Oral Surgery, Faculty of Dentistry, Wrocław Medical University, Poland \\ ${ }^{2}$ Academic Dental Polyclinic in Wrocław, Poland \\ A - research concept and design; $\mathrm{B}$ - collection and/or assembly of data; $\mathrm{C}$ - data analysis and interpretation; \\ $D$ - writing the article; $E$ - critical revision of the article; $F$ - final approval of the article
}

Address for correspondence

Kamil Jurczyszyn

E-mail: kjurczysz@interia.pl

Funding sources

None declared

Conflict of interest

None declared

\section{Acknowledgements}

This work was supported by the National Centre for Research and

Development (NCBR), Poland (No. PBS3/A7/18/2015 "LASDER").

Received on September 26, 2018

Reviewed on October 23, 2018

Accepted on December 5, 2018

Published online on March 29, 2019

Cite as

Trafalski M, Kazubowska K, Jurczyszyn K. Treatment of the facial basal cell carcinoma with the use of photodynamic therapy: A case report. Dent Med Probl. 2019;56(1):105-110. doi:10.17219/dmp/100507

DOI

$10.17219 / \mathrm{dmp} / 100507$

Copyright

๑ 2019 by Wroclaw Medical University

This is an article distributed under the terms of the

Creative Commons Attribution Non-Commercial License

(http://creativecommons.org/licenses/by-nc-nd/4.0/)

\begin{abstract}
Basal cell carcinoma (BCC) is the most common skin cancer. It accounts for approx. 80\% of human skin cancers and belongs to the group of non-melanoma skin cancers (NMSC). The highest incidence of this cancer is visible in older people, over 65 years of age. Photodynamic therapy (PDT) is a clinically approved method with a selective cytotoxic activity. It is used in the treatment of superficial forms of BCC, precancerous conditions (hyperkeratosis, actinic keratosis) and non-cancerous diseases (acne vulgaris, infection with herpes simplex virus - HSV, leukoplakia, lichen planus).

The aim of the study was to apply PDT to a patient with a clinical diagnosis and histopathologically confirmed BCC.

The patient, male, aged 82, reported to the Department of Oral Surgery at Wroclaw Medical University with $B C C$ of dimensions $0.5 \times 1.5 \mathrm{~cm}$, present for 13 years in the area of the right mandibular angle, after previous surgical treatment. Photodynamic diagnosis (PDD) and PDT were employed using a semiconductor laser. 5-aminolevulinic acid (5-ALA) was used as a photosensitizer. The PDD and PDT procedures were applied at 2-week intervals for 3 months. Control visits after 3, 6 and 12 months did not show local recurrence. Photodynamic therapy is a highly useful, independent method of treating superficial forms of $B C C$.
\end{abstract}

Key words: basal cell carcinoma, photodynamic therapy, photodynamic diagnosis, aminolevulinic acid

Słowa kluczowe: rak podstawnokomórkowy, terapia fotodynamiczna, diagnostyka fotodynamiczna, kwas aminolewulinowy 


\section{Introduction}

Basal cell carcinoma (BCC) is the most common skin cancer. It accounts for approx. $80 \%$ of human skin cancers and belongs to the group of non-melanoma skin cancers (NMSC). The highest incidence of this cancer is visible in older people, over 65 years of age, but in recent years, a significant increase in the incidence of BCC among young people has been observed. ${ }^{1}$ The most common $\mathrm{BCC}$ locations include exposed parts of the body, such as the nose, forehead, upper lip, nasolabial fold, eyelids, and $90 \%$ of lesions are placed between the hairline and the upper lip. Furthermore, BCC may also appear in other areas (the back, shoulders, dorsal parts of the hands). ${ }^{2,3}$ In relation to sex, men are slightly more likely to get ill. The main factor triggering this disorder is ultraviolet radiation, especially UVB (280-320 nm). This correlates with the highest number of cases in areas with high insolation. Additional features that predispose to carcinogenesis include skin contact with hydrocarbon or arsenic, ionizing radiation, human papilloma virus (HPV), as well as Gorlin and Goltz's syndrome. In the area of the head, BCC grows in the form of a nodule with heaped-up edges, often with central ulceration or as a red spot with minor ulcers, often with a central cavity and centers of more intense pigmentation (partially covered with a scab). On the other hand, in the area of the trunk, the macroscopic image is different. The cancer is presented as flat and brown lesions with delicate exfoliation on the surface, with elevated borders. The tumor shows slow growth and low local malignancy rates, rarely leading to distant metastases. ${ }^{4}$ Long-term growth of untreated tumor causes extensive destruction of the skin, as well as destruction of the neighboring tissues, posing a significant threat to important anatomical structures, in particular in the area of the head and neck.

Basal cell carcinoma is derived from cells found in the basal layer of the epidermis. Histologically, the following forms of BCC have been distinguished: solidum, cysticum, adenoides, keratoticum, pigmentosum, superficiale multicentricum (located mainly on the trunk and limbs), cicatricans, and styloides - it is characterized by the least favorable prognosis; it grows deeper in the form of a separating strand that penetrates tissues. ${ }^{5}$ Diagnostics of BCC usually does not cause any problems during an interview and physical examination of the patient. However, the final verification and diagnosis is based on a histopathological examination of the lesions - entirely cut out or their fragments.

In the treatment of $\mathrm{BCC}$, surgical treatment remains the golden standard, but due to the limitations of this method in the particularly sensitive or esthetically important areas, behavioral methods play an important role and they include the following: photodynamic therapy (PDT), radiotherapy and local pharmacotherapy.
In contrast, invasive methods include methods involving the excision of the lesion and ablative methods, based on destruction of pathological tissue, such as freezing, laser therapy and curettage, supplemented by electrodesiccation of tissues. For esthetic reasons, the tumor often cannot be cut out with the right margin, which results in later local recurrence. In these cases, an invaluable advantage is given by non-invasive methods, which include, among others, PDT.

Photodynamic therapy is a clinically approved method with a selective cytotoxic activity. It is used for the treatment of superficial forms of BCC, precancerous conditions (hyperkeratosis, actinic keratosis) and non-cancerous diseases (acne vulgaris, infection with herpes simplex virus - HSV, leukoplakia, lichen planus) ${ }^{6-9}$ However, PDT is used for small and superficial lesions located on the skin and mucosa. The effectiveness of PDT is limited mainly by the ability of light to penetrate into tissues (approx. $3 \mathrm{~mm}$ ). It is particularly recommended in the treatment of superficial BCC (sBCC). ${ }^{10}$

The main components of PDT are a compound called a photosensitizer and light. As a result of the absorption of energy coming from an incident light wave, the photosensitizer goes into an excited state. Excitation of the photosensitizer and transfer of the excess energy around the intracellular structures and tissues lead to a series of cytotoxic reactions, resulting in necrosis or induction of apoptosis. One of the widely used compounds which act as photosensitizers are porphyrin derivatives. These compounds have a maximum absorption around $405 \mathrm{~nm}$. Therefore, it would seem that the best source of light to excite this group of photosensitizers is a light-emitting source in this range. Due to the presence of melanocytes, the skin and mucous membranes strongly attenuate ultraviolet radiation, which is why light in the range from blue to near infrared is used in PDT. Transmission of light in the skin and mucosa is increased along with the wavelength. In order to achieve greater effectiveness of PDT in deeper layers of the treated lesions, photosensitizers whose absorption window falls within the range from $600 \mathrm{~nm}$ to near infrared are used. Due to the fact that porphyrin-based photosensitizers have a high affinity for cells with increased metabolism, it is possible to preserve PDT selectivity only for the treated lesions. In addition to photosensitizers, their precursors are also used in PDT. One of the most frequently used precursors of protoporphyrin IX is 5-aminolevulinic acid (5-ALA) and its methyl derivative (MAL).

\section{Case report}

The patient, R.R. (man), aged 82, suffering from arterial hypertension, reported to the Department of Oral Surgery at Wroclaw Medical University concerned about a lesion 
of dimensions $0.5 \times 1.5 \mathrm{~cm}$, which had been recurring for 13 years in the area of the right mandibular angle (Fig. 1) after surgical treatment. Figure 2 shows the lesion during PDD - red fluorescence of the photosensitizer indicates neoplasm cells. Before the implementation of the treatment, a clinical diagnosis was confirmed by a histopathological examination. For 3 months, the patient had PDD at 2-week intervals and he was treated with PDT.

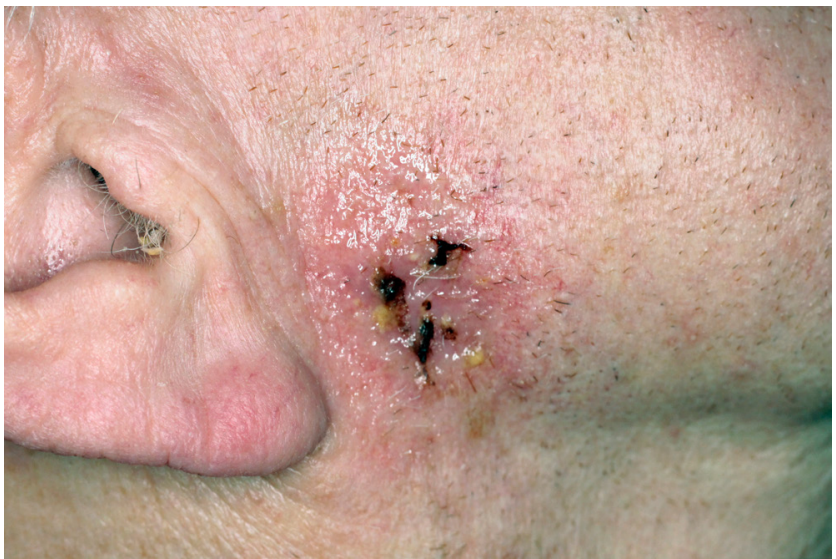

Fig. 1. Local state of patient before treatment

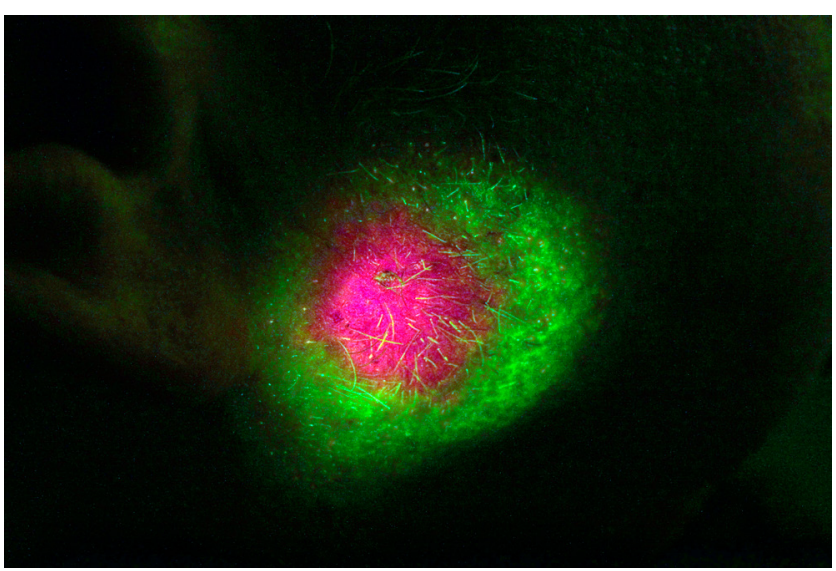

Fig. 2. Lesion during photodynamic diagnosis (PDD) - red fluorescence of photosensitizer indicates neoplasm cells

The treatment algorithm for PDT and PDD was as follows: clinical examination; collection of photographic documentation; local application of the photosensitizer on the BCC site - 20\% 5-ALA ointment on eucerin base (Sigma-Aldrich, St. Louis, USA); after 2 h, PDD carried out with the following exposure parameters: wavelength - $405 \mathrm{~nm}, 50 \mathrm{~mW} / \mathrm{cm}^{2}$, source of radiation - a semiconductorlaser (developedby professor Witold Trzeciakowski, Polish Academy of Science, Warszawa, Poland, patent No. 9223123 B2); photographic documentation during the PDD procedure; after PDD, another application of the photosensitizer -20\% 5-ALA covered with dressing - for another $2 \mathrm{~h}$; PDT carried out with the following parameters: wavelength $-630 \mathrm{~nm}, 250 \mathrm{~mW} / \mathrm{cm}^{2}$, total energy - $120 \mathrm{~J}$, source of radiation - the above-mentioned semiconductor laser. After 3 months, the BCC outbreak partially regressed. Figure 3 presents the local condition. After another 3 months, the patient reported to the control visit - no recurrence was found (Fig. 4). The next control was performed 9 months after the procedure. There was no local recurrence in the postoperative area. The state after a period of 12 months is shown in Fig. 5. Photodynamic diagnosis after 12 months is shown in Fig. 6 - there is no red fluorescence of the photosensitizer, which indicates there are no more neoplasm cells. Figure 7 shows a standard histological pattern of BCC before treatment (magnification $\times 100$, hematoxylin-eosin $(H \& E)$ stain).

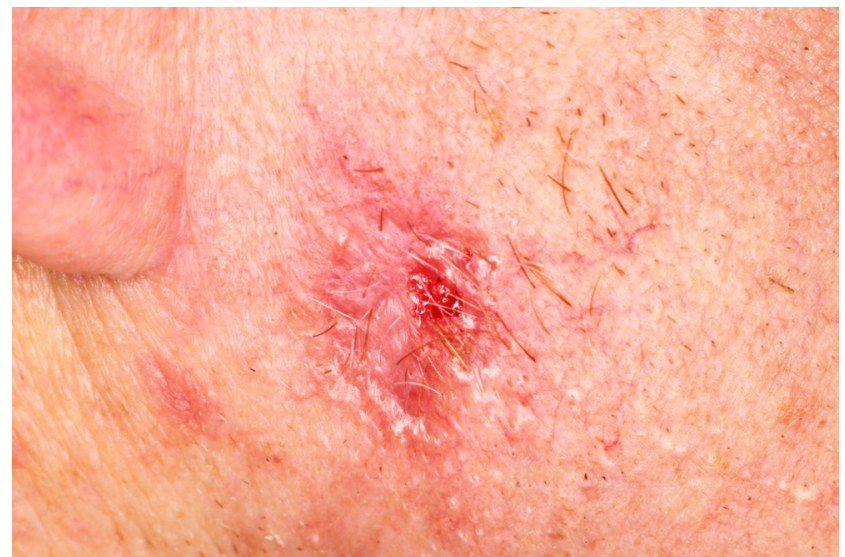

Fig. 3. Local state after 3 months

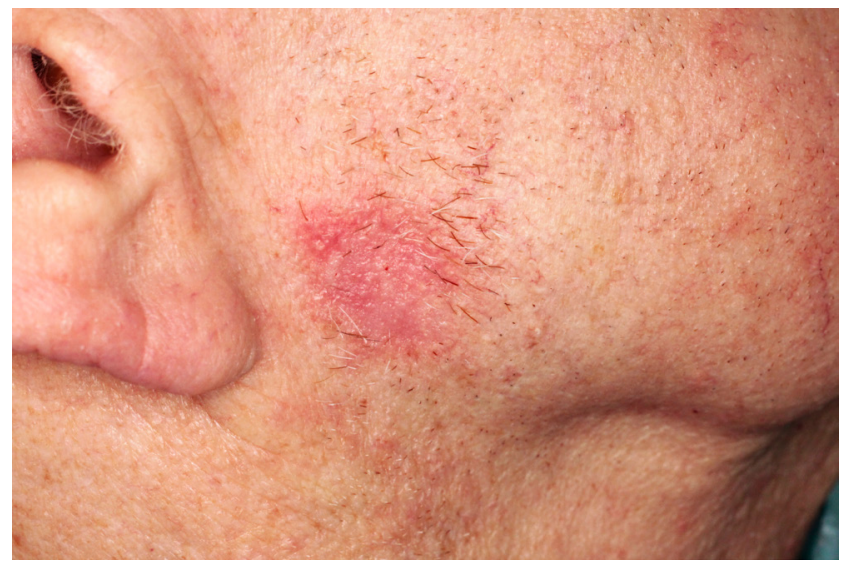

Fig. 4. Local state after 6 months

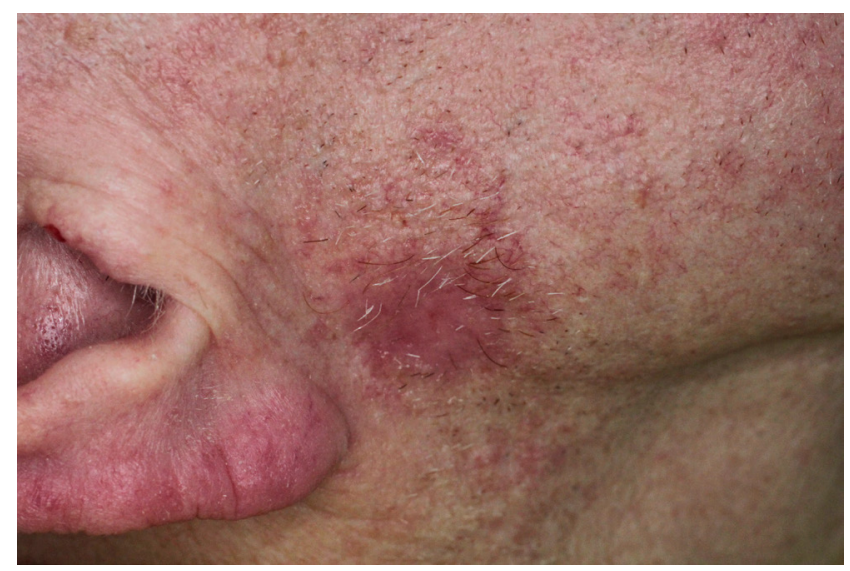

Fig. 5. Local state after 12 months 


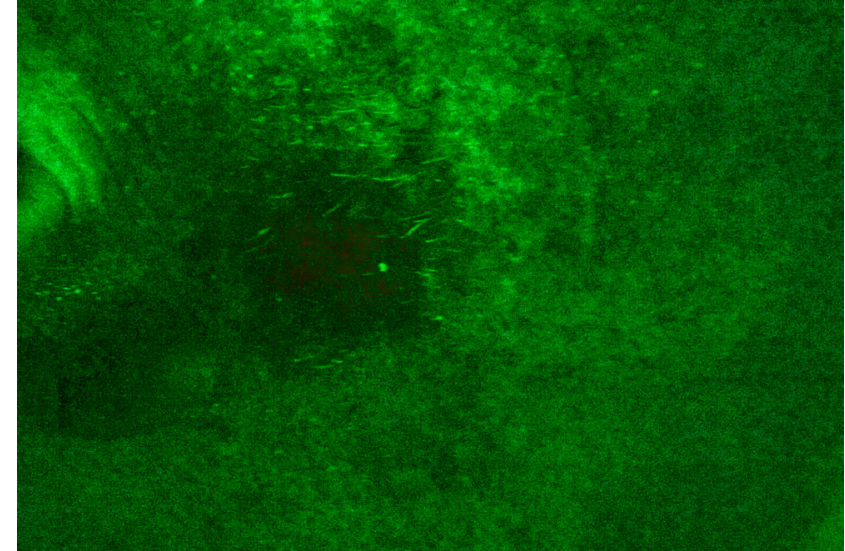

Fig. 6. Photodynamic diagnosis (PDD) procedure after 12 months - there is no red fluorescence of photosensitizer

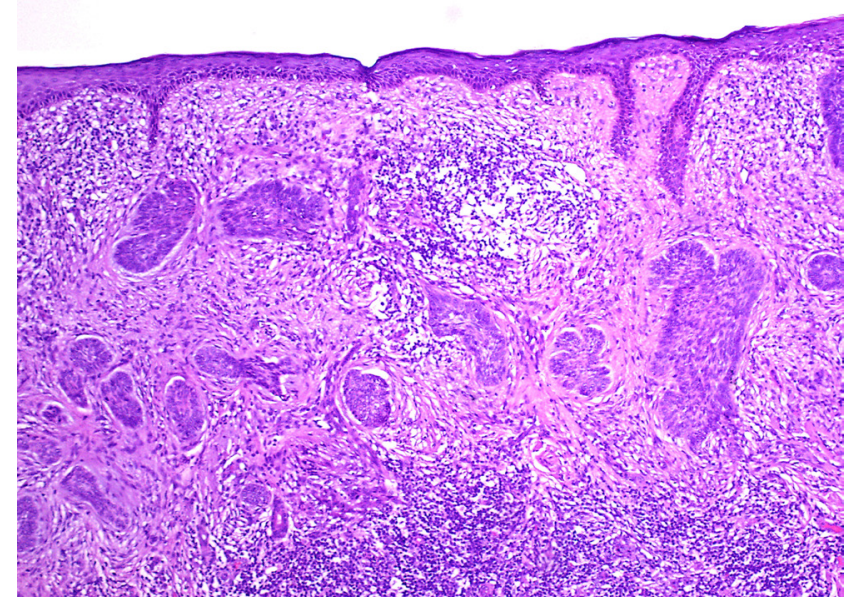

Fig. 7. Standard histological pattern of basic cell carcinoma (BCC) before treatment (magnification $\times 100$, hematoxylin-eosin (H\&E) stain

\section{Discussion}

Factors that should be taken into account before the selection of a treatment strategy for BCC include, among others, the following: degree of advancement and size of the tumor, infiltration of the tumor into the adjacent tissues, location of the tumor, general condition of the patient, and any previous treatment of the lesion. Among the many possible therapies, surgical treatment of BCC remains the golden standard. It ranks first among the methods with the lowest numbers of relapses in the 5-year period after the end of treatment $-98.6 \%$ effectiveness in primary BCC and $96 \%$ efficiency in secondary BCC. ${ }^{11}$ In comparison with conservative therapies, surgical treatment gives the opportunity to evaluate the radicality of the resection of the tumor by performing intraoperative examinations with the use of the Mohs micrographic surgery (MMS). Moreover, it provides the final histopathological verification of the tumor, which is impossible with the use of conservative methods. The Mohs micrographic surgery is based on precise excision of lesions due to a histopathological examination of the edges in the removed tissues. This technique gives the maximum possibility of saving healthy tissues and it is recommended especially in areas requiring high esthetics after treatment, such as the face. Furthermore, it is preferred in the cases of recurrent BCC lesions with poorly marked borderlines and tumors exceeding $2 \mathrm{~cm}$ in diameter. The Mohs micrographic surgery gives less recurrence over a 5 -year period compared to classical tumor excision. ${ }^{12,13}$ When determining the extent of the surgical margin for BCC, the doctor should be guided mainly by the diameter of the tumor. Therefore, it is assumed that for lesions not exceeding $2 \mathrm{~cm}$ in diameter, a margin of $3 \mathrm{~mm}$ ensures effective resections in $85 \%$ of the cases and a 5-millimeter margin guarantees successful resections in $95 \%$ of the cases. ${ }^{5}$ This significantly affects the post-operative esthetic effect in a given anatomical area, which is very important for the head and neck region. Scars after surgical treatment depend mainly on the extent of the tumor and the method of closing the defect in the resected tissues. Apart from the excised lesions in the treatment area, healthy tissues are often also excised in order to collect skin patches used to close the primary cavity. This procedure significantly increases the surgical area above the correct surgical margin of the resected tumor.

However, there are situations, especially in the head area, where the determination of a sufficient margin is limited by the presence of important anatomical structures, such as the eyeballs, eyelids and earlobes. In these cases, there are methods that work outstandingly selectively against cancer cells. They include PDT, local therapy with 5\% imiquimod and 5-fluorouracil (5-FU), and targeted molecular therapy with vismodegib, all of which specifically save the healthy tissues adjacent to the tumor.

Comparing the response to treatment in the case of a surgical method and PDT with MAL as a photosensitizer (MAL-PDT), a complete response at the level of $96 \%$ for the surgical method and 73\% for PDT (in the observation period of 5 years) has been shown. ${ }^{14}$ However, when analyzing the esthetic effect of both methods obtained after the treatment, PDT significantly exceeds the surgical treatment. ${ }^{14-16}$ Therefore, PDT has become an alternative method for patients excluded from the surgical treatment due to general health reasons and for patients in whom, because of the location of the lesion, scarring after the surgical treatment would disrupt the esthetic effect.

Methods including topical pharmacological therapy are mainly used for the treatment of small-size tumors. In these cases, imiquimod can be used. This is a modulator of the immune response, especially in the field of dendritic cells and monocytes. It has been approved by the Food and Drug Administration (FDA) and the European Medicines Agency (EMA) for the treatment of $\mathrm{BCC}$ with a diameter not exceeding $2 \mathrm{~cm}$. In addition to anticancer activity, it is used in the treatment of viral diseases, especially related to HPV. It is used in the form of $5 \%$ cream in occlusive dressings, depending on the form of $\mathrm{BCC}$, from 6 to 12 weeks, 5-6 times a week. A comparison of local treatment with the use of $5 \%$ imiquimod for 6 weeks 
in $\mathrm{SBCC}$ and for 12 weeks in the nodular form of $\mathrm{BCC}$ with the classical surgical excision showed a 5-year cure rate at the level of $82.5 \%$ for the group treated with imiquimod and $97.7 \%$ for the group where the lesion was excised. ${ }^{17}$ Imiquimod is generally well-tolerated by patients, and the most common side effects observed during therapy are erythema, scabs, erosions, or dermatitis. The conducted research comparing the topical therapy with imiquimod and MAL-PDT showed a slightly higher effectiveness of the imiquimod treatment in the period of 3 months and 12 months $-83.4 \%$ of patients fully responding to the treatment in relation to $72.8 \%$ in the case of MAL-PDT. ${ }^{18}$

Another topical treatment of BCC, approved by FDA, is the 5-FU therapy. 5-fluorouracil is a locally used pyrimidine analog in the form of a cream which acts as an antimetabolite disturbing the local DNA synthesis. Pilot studies on the efficiency of this monotherapy demonstrated $90 \%$ of responses to the treatment with $5 \%$ cream with 5 -FU on the phosphatidylcholine substrate. Among patients treated with 5-FU on the petrolatum substrate, a positive response was received in $57 \%$ of the lesions. ${ }^{19}$ Other studies examined the effectiveness of MAL-PDT compared to the 5-FU therapy. These examinations showed that the percentage of patients fully responding to the treatment in the period of 3 months and 12 months was $72.8 \%$ for MAL-PDT and $80.1 \%$ for the 5 -FU therapy. Patients after local pharmacotherapy more often reported moderate or severe swellings, erosions, scab formation, and itchy skin compared to patients treated with MAL-PDT. On the other hand, during MAL-PDT, moderate or severe pain, burning sensation and redness of the skin were most commonly reported. ${ }^{18}$

Non-invasive BCC treatment methods include molecular therapy with the use of vismodegib. It works by interrupting the Hedgehog signaling pathway, which becomes excessively active in BCC. Vismodegib is an inhibitor of Smoothened transmembrane protein (SMO), involved in the activation of the Hedgehog pathway. By blocking this pathway, vismodegib inhibits the development of the tumor and slows down its growth. In 2012, it was approved by FDA for the treatment of $\mathrm{BCC}$ metastases, recurrence after the resection of the tumor, and for the treatment of patients excluded from surgery and radiotherapy. The Safety Events in VIsmodEgib study (STEVIE) is one of the largest examinations involving the use of vismodegib. It showed $66.7 \%$ of responses in patients with locally advanced BCC and $37.9 \%$ of responses in patients with a metastatic form of BCC. Patients took orally $150 \mathrm{mg}$ of vismodegib in 28-day cycles. The median of response time was 22.7 months, with an average treatment time of 36.4 weeks. Side effects during the treatment were reported in $98 \%$ of patients. The most common side effects are the following: muscle spasms (64\%,) baldness (62\%), taste disorders $(54 \%)$, weight loss $(33 \%)$, fatigue $(28 \%$,) decreased appetite (25\%), and diarrhea (18\%). ${ }^{20}$

Furthermore, there are reports on the possibility of combining PDT with vismodegib. The research conducted in this direction showed that the combined therapy was well-tolerated by patients. The percentage of responses to the treatment was 90\% (total) and 10\% (partial) responses within 30 days since the end of the therapy. The combination of vismodegib and PDT is a potentially safe and effective therapy in the treatment of BCC. It increases the effectiveness of individual therapies, while maintaining a perfect cosmetic effect. ${ }^{21}$

Among the invasive methods of BCC treatment, cryotherapy (i.e., local freezing) deserves special attention. It involves the application of a freezing agent in the form of liquid nitrogen at a temperature of approx. $-196^{\circ} \mathrm{C}$ to the pathological lesion, thus causing local tissue necrosis. In order to destroy BCC tumor cells, it is necessary to achieve a temperature in the tissue at the level of $-50^{\circ} \mathrm{C}$ with 2 freezing and thawing cycles. ${ }^{22}$ Cryotherapy, just like PDT, is applicable to the treatment of small and superficial forms of BCC. Conducted research concerning the comparison of cryotherapy and MAL-PDT in the treatment of sBCC has shown the response to treatment at a similar level. During a 5-year period, recurrence of the diseases at the level of 22\% for MAL-PDT and $20 \%$ for cryotherapy was observed. However, the cosmetic effect obtained with the use of PDT significantly exceeded the results received after the use of cryotherapy, since healing after freezing very often leaves scars and discoloration on the skin. ${ }^{23}$ August believes that this method should be avoided in the treatment of BCC on the scalp and in the nasolabial folds due to the large number of recurrences after the treatment. ${ }^{24}$ Ceilley and Del Rosso also mentioned that cryotherapy can cause recurrence due to the survival of the tumor in the fibrous stroma of the scar. ${ }^{25}$ Moreover, there was also an attempt to combine PDT with $\mathrm{CO}_{2}$ laser ablation and modified cryotherapy. This attempt demonstrated high efficiency and a good cosmetic effect in the treatment of BCC in the nodular form. ${ }^{26}$

\section{Conclusions}

In the light of the above-mentioned factors, PDT is a highly useful, independent method of treating superficial forms of BCC. Furthermore, it provides a satisfactory effect in combination with other therapeutic options. Due to its advantage over other therapies in the form of highly selective action toward cancer cells and very good cosmetic results after the treatment, it has become an important alternative to other approaches, especially in esthetically sensitive areas, such as the head and neck. Studies on PDT with regard to $\mathrm{sBCC}$ show satisfactory treatment response rates. The surgery procedures are recommended for the treatment of BCC, but in special cases, PDT could be applied. Therefore, it can be considered as a reasonable therapeutic option, especially for patients who do not accept possible surgical complications or for patients excluded from the surgical treatment. 


\section{ORCID iDs}

Mateusz Trafalski (D) https://orcid.org/0000-0002-7643-9664 Klaudia Kazubowska (i) https://orcid.org/0000-0003-3934-4305 Kamil Jurczyszyn (D) https://orcid.org/0000-0002-0667-7261

\section{References}

1. Nejc D, Piekarski J, Pasz-Walczak G, Jeziorski A. Basal cell carcinoma of the skin - the young age of the patients causes diagnostic doubts [in Polish]. Onkol Pol. 2002;5(3-4):179-181.

2. Yaghoobi R, Ranjbari N, Pazyar N, Foroozan M, Feily A. Basal cell carcinoma of vermilion mucosa of upper lip: A rare case report. Acta Med Indones. 2017;49(3):255-258.

3. Loh T, Rubin AG, Brian Jiang SI. Management of mucosal basal cell carcinoma of the lip: An update and comprehensive review of the literature. Dermatol Surg. 2016;42(12):1313-1319.

4. Snow SN, Sahl W, Lo JS, et al. Metastatic basal cell carcinoma. Report of five cases. Cancer. 1994;73(2):328-335.

5. Pabiańczyk R, Cieślik K, Tuleja T. Management methods of basal cell carcinoma [in Polish]. Chir Pol. 2011;13(1):48-58.

6. Taub AF. A comparison of intense pulsed light, combination radiofrequency and intense pulsed light, and blue light in photodynamic therapy for acne vulgaris. J Drugs Dermatol. 2007;6(10):1010-1016.

7. Tao JN, Duan SM, Li J. Experimental studies on treatment of HSV infections with photodynamic therapy using 5 -aminolevulinic acid [in Chinese]. Zhonghua Shi Yan He Lin Chuang Bing Du Xue Za Zhi. 2007;21(1):79-82.

8. Chen HM, Yu CH, Tu PC, Yeh CY, Tsai T, Chiang CP. Successful treatment of oral verrucous hyperplasia and oral leukoplakia with topical 5-aminolevulinic acid-mediated photodynamic therapy. Lasers Surg Med. 2005;37(2):114-122.

9. Aghahosseini F, Arbabi-Kalati F, Fashtami LA, Fateh M, Djavid GE. Treatment of oral lichen planus with photodynamic therapy mediated methylene blue: A case report. Med Oral Patol Oral Cir Bucal. 2006;11(2):E126-E129.

10. Rhodes LE, de Rie M, Enström Y, et al. Photodynamic therapy using topical methyl aminolevulinate vs surgery for nodular basal cell carcinoma: Results of a multicenter randomized prospective trial. Arch Dermatol. 2004;140(1):17-23.

11. Leibovitch I, Huilgol SC, Selva D, Richards S, Paver R. Basal cell carcinoma treated with Mohs surgery in Australia II. Outcome at 5-year follow-up. J Am Acad Dermatol. 2005;53(3):452-457.

12. Mosterd K, Krekels GA, Nieman FH, et al. Surgical excision versus Mohs' micrographic surgery for primary and recurrent basal-cell carcinoma of the face: A prospective randomised controlled trial with 5-years' follow-up. Lancet Oncol. 2008;9(12):1149-1156.

13. Smeets NW, Kuijpers DI, Nelemans $P$, et al. Mohs' micrographic surgery for treatment of basal cell carcinoma of the face - results of a retrospective study and review of the literature. Br J Dermatol. 2004;151(1):141-147.

14. Roozeboom MH, Aardoom MA, Nelemans PJ, et al. Fractionated 5-aminolevulinic acid photodynamic therapy after partial debulking versus surgical excision for nodular basal cell carcinoma: A randomized controlled trial with at least 5-year follow-up. J Am Acad Dermatol. 2013;69(2):280-287.

15. Rhodes LE, de Rie MA, Leifsdottir R, et al. Five-year follow-up of a randomized, prospective trial of topical methyl aminolevulinate photodynamic therapy vs surgery for nodular basal cell carcinoma. Arch Dermatol. 2007;143(9):1131-1136.

16. Bath-Hextall FJ, Perkins W, Bong J, Williams HC. Interventions for basal cell carcinoma of the skin. Cochrane Database Syst Rev. 2007;24(1):CD003412.

17. Williams HC, Bath-Hextall FJ, Ozolins $M$, et al. Surgery versus $5 \%$ imiquimod for nodular and superficial basal cell carcinoma: 5-year results of the SINS randomized controlled trial. J Invest Dermatol. 2017;137(3):614-619.

18. Arits AH, Mosterd K, Essers BA, et al. Photodynamic therapy versus topical imiquimod versus topical fluorouracil for treatment of superficial basal-cell carcinoma: A single blind, non-inferiority, randomized controlled trial. Lancet Oncol. 2013;14(7):647-654.
19. Romagosa R, Saap $L$, Givens $M$, et al. A pilot study to evaluate the treatment of basal cell carcinoma with 5 -fluorouracil using phosphatidylcholine as a transepidermal carrier. Dermatol Surg. 2000;26(4):338-340.

20. Basset-Seguin N, Hauschild A, Grob JJ, et al. Vismodegib in patients with advanced basal cell carcinoma (STEVIE): A pre-planned interim analysis of an international, open label trial. Lancet Oncol. 2015;16(6):729-736.

21. Rizzo JM, Segal RJ, Zeitouni NC. Combination vismodegib and photodynamic therapy for multiple basal cell carcinomas. Photodiagnosis Photodyn Ther. 2018;21:58-62.

22. Nakayama M, Tabuchi K, Nakamura Y, Hara A. Basal cell carcinoma of the head and neck. J Skin Cancer. 2011;2011:496910.

23. Basset-Seguin N, Ibbotson SH, Emtestam L, et al. Topical methyl aminolaevulinate photodynamic therapy versus cryotherapy for superficial basal cell carcinoma: A 5 year randomized trial. Eur J Dermatol. 2008;18(5):547-553.

24. August PJ. Cryotherapy of nonmelanoma skin cancer. Clin Dermatol. 1995;13(6):589-592.

25. Ceilley RI, Del Rosso JQ. Current modalities and new advances in the treatment of basal cell carcinoma. Int J Dermatol. 2006;45(5):489-498.

26. Kim SA, Lee KS, Cho JW. Photodynamic therapy combined with cryotherapy for the treatment of nodular basal cell carcinoma. Oncol Lett. 2013;6(4):939-941. 